\title{
AGAINST JEFFREY HOWARD ON ENTRAPMENT
}

\author{
Jonathan Stanhope
}

II

MAGINE WICKED BARRY, impressionable Carl, and innocent Leila. Suppose Barry fosters in Carl an intention to kidnap and torture Leila, in a way that does not negate Carl's moral responsibility. ${ }^{1}$ (It does not amount to brainwashing, say.) Hence, if Carl actually does kidnap and torture Leila, he wrongs her. And Barry wrongs Leila too, by culpably encouraging Carl.

Plausibly, this completes the catalog of wrongs in our example. But in a recent paper, Jeffrey Howard develops an intriguing argument to the contrary. ${ }^{2} \mathrm{He}$ contends that, by inducing Carl to do wrong, Barry wrongs Carl. Ironically, Carl shares something with Leila: a complaint against Barry.

The implications of Howard's argument_if correct-are profound. First, entrapment by law enforcers is wrong even if it does not lead to the prosecution or punishment of the entrapped person. ${ }^{3}$ Second, the wrong of entrapment is, ceteris paribus, indistinguishable from the wrong committed by private citizen Barry. Third, governments wrong many of their citizens in entrapment-like ways through policies that make it rational for them to act wrongly. For example, inadequate education, job scarcity, and permissive firearms laws foreseeably encourage some citizens to join criminal gangs. Consequently, our obligations to reform or transform prevailing political and socioeconomic conditions are even stronger than we initially thought. ${ }^{4}$

Howard's animating idea is that inducements to do wrong subvert or interfere with the induced agent's moral capacities. ${ }^{5} \mathrm{He}$ believes that we each have a categorical, constraint-imposing duty not to foreseeably increase the likelihood that another agent (culpably) acts wrongly-hereafter DUTY-that is grounded

1 Elaboration of an example in Howard, "Moral Subversion and Structural Entrapment," 2930.

2 Howard, "Moral Subversion and Structural Entrapment."

3 Nor any other harm, such as reputational damage.

4 Howard, "Moral Subversion and Structural Entrapment," 45-46.

5 Howard, "Moral Subversion and Structural Entrapment," 25. 
in a more basic obligation "to respect the first moral power" - hereafter FMP—of that agent. ${ }^{6}$

I accept the existence of the more basic obligation. Nonetheless, whether it entails DUTY, and thereby condemns entrapment and neighboring phenomena, depends on how FMP's value is grounded. For Howard, the value of FMP is such as to demand a regulative attitude of support for FMP's successful exercise rather than its exercise per se. ${ }^{7}$ In what follows, I offer a more nuanced account of the value of FMP, one more attuned to certain liberal thoughts about agency. This undermines Howard's case for DUTY, and by extension his case against entrapment and its neighbors. (A fact that, I conclude, proves especially significant for the all-things-considered permissibility of entrapment by law enforcers.) Still, in a constructive spirit, I also sketch a different argument for DUTY. Though it does not yet persuade me, I hope it can be developed in a compelling direction.

Borrowing from John Rawls, Howard construes moral agency in terms of two moral powers. ${ }^{8}$ In doing so, he notes that the second — the capacity to set, revise, and pursue a conception of one's rational advantage- has received much greater attention in liberal political philosophy than the first. Whereas the second is central to autonomy-based arguments against paternalism and perfectionism, for instance, the first rarely receives extensive discussion. ${ }^{9}$ Howard's focus on FMP is a welcome change.

On Howard's definition, FMP is an "agent's capacity to reason about right and wrong and to regulate his conduct by the conclusion of his reasoning." ${ }^{10}$ This, quite properly, omits any reference to correctness: FMP can lead the agent to defective conclusions, or-as with akrasia—fail to generate right conduct even when the agent has moral knowledge. Yet in outlining what respect for FMP involves, Howard writes that one aspect is "recognizing the power's existence: the person's capacity to reason about the demands of morality and live up to those

6 Howard, "Moral Subversion and Structural Entrapment," 31.

7 Neither I nor Howard presuppose a realist interpretation of moral rightness. As per constructivism, reaching correct moral judgments might consist in, rather than being facilitated by, valid reasoning.

8 Rawls, Political Liberalism, 48-54.

9 Howard, "Moral Subversion and Structural Entrapment," 29-30. Though the first surfaces repeatedly, for example, there are no prolonged discussions of FMP in Freeman, The Cambridge Companion to Rawls, or Mandle and Ready, A Companion to Rawls.

10 Howard, "Moral Subversion and Structural Entrapment," 29. Strictly speaking, then, FMP is a bundle of powers, both cognitive and conative. 
demands." ${ }^{11}$ Not what the agent thinks are those demands, but simply those demands, period.

In addition, Howard argues that the second, more demanding component of such respect is a regulative attitude of support for FMP's successful exercise. And this follows from the idea that "the value of the first moral power inheres largely in its successful exercise." ${ }^{12}$ To respect FMP is to respect its proper functioning, given that FMP's value is grounded in the value of the right conduct it enables. Since foreseeably increasing the likelihood that another agent acts wrongly is incompatible with respecting FMP, it is wrong. (The flip side of this is, of course, DUTY.) Furthermore, it wrongs the agent whose FMP is subverted: her moral agency is disrespected. ${ }^{13}$

According to Howard, a wide range of actions count as violations of DUTY. ${ }^{14}$ As well as actions that affect conation, such as incitement and temptation, they also include moral-epistemic subversion, where false beliefs about the content of morality or its proper role in practical reasoning are fostered. For example, inculcating the belief that moral reasons are no more decisive or regulative than nonmoral reasons raises the chance that the misled agent will overlook or underweight them. ${ }^{15}$

Note that I accept—at least for the sake of argument—-Howard's key assumption that nonmoral reasons cannot override moral reasons. FMP's deliverances should be the verdict of practical reasoning generally, even when this just means rubber-stamping the deliverances of the second moral power. With Howard, I will not allow for subversions of FMP that respect the agent's overall practical powers in virtue of giving her overriding reason to act immorally.

As stated, my objection is to cashing out the value of FMP in terms of its successful exercise. Howard does not defend this move at length, merely claiming

11 Howard, "Moral Subversion and Structural Entrapment," 30.

12 Howard, "Moral Subversion and Structural Entrapment," 30.

13 Howard presumably thinks the degree to which it wrongs the agent is a function of the degree to which it foreseeably increases the probability of her acting wrongly.

14 Importantly, Howard constrains DUTY-violating actions to actions unprotected by an antecedent right. Howard believes that, if it were even pro tanto wrong for a person to visit a neighborhood where her skin color elevates the chance of her being assaulted, then it would be appropriate for her to feel regret. Additionally, "fundamental standards of justice" would vary with different probabilities of compliance with them. Both implications are, in Howard's view, implausible. See "Moral Subversion and Structural Entrapment," 32.

Howard, "Moral Subversion and Structural Entrapment," 31. 
that agents expect-normatively speaking—right conduct from each other. ${ }^{16}$ Of course, all going well, FMP does allow agents to meet these expectations. We might even say that it aims at meeting them, that it has such a telos. In exercising FMP, however, we are trying to discern relevant principles, how to prioritize them, how they interact, and what prescriptions they issue when conjoined with nonmoral facts. We are also trying to integrate these prescriptions into our practical lives so that, in addition to acting as we see right, we find the experience tolerable and hopefully enriching. Aiming to meet normative expectations is aiming to respond to reasons, and is thus characteristically deliberative.

Exercising FMP, then, exemplifies our agency. And it does so whether it leads to right or wrong conduct. Howard's silence on this possibility is odd given that he criticizes paternalism for disrespecting the second moral power. The standard liberal claim about the value of the capacity for a conception of one's good is not that, left to its own devices, the capacity tends to promote one's good. ${ }^{17}$ Instead, the claim is that we exemplify agency when we decide for ourselves what lives to lead and how to lead them, even if we decide wrongly. Liberals typically are not skeptical of the existence of an agent's good, nor the suggestion that she might fail to understand or realize it. Rather, they tend to dispute the permissibility of-or place justificatory obstacles in the way of-interfering as such with (uncoerced, self-regarding) choices.

Something similar can be said about the value of FMP. Agency is exemplified no less when we reason about how to treat others, and act on that reasoning, than when we reason about our personal fulfilment, and act on that reasoning. True, we might distinguish between personal and moral autonomy, and make it a necessary-and perhaps sufficient-condition of moral autonomy that the agent acts rightly. But that will not stop defective exercises of FMP from exemplifying agency, unless agency just is, or depends on, moral autonomy. Patently, though, it is a demerit for arguments in practical ethics to rely-as Howard does not-on the (presumably) Kantian backstory that would be required. Moreover, even if FMP's value is not connected to agency, it has everything to do with (what we might call) shmagency, reflective choice under a different label. ${ }^{18}$

Howard, "Moral Subversion and Structural Entrapment," 30.

In a slogan, "to be able to choose is a good that is independent of the wisdom of what is chosen." See Dworkin, "Paternalism," 72. Whether the value of agency must be justifiable in the qualified terms of public reason is an object of disagreement between liberals.

I am shamelessly borrowing the term from Enoch, "Agency, Shmagency." 
So, it is not promising to exclude from an account of FMP's value the idea of exemplifying agency. At this point, however, it becomes crucial to note that general talk of FMP's value is actually extremely unhelpful. For it is not relevant whether, as Howard believes, the value of FMP is grounded largely in its successful exercise. If FMP demands a regulative attitude of support, rather than being supported when and because it succeeds as a means to a valuable end, this must be because it has final value, value for its own sake. ${ }^{19}$ But nothing Howard says indicates that the value of FMP, when successfully exercised, goes beyond its instrumental value. Nor does he clarify how the mere abstract potential for FMP to facilitate right action could be sufficient to confer final value on a particular agent's FMP when she exercises it unsuccessfully. Why not conclude that the abstract potential for FMP to facilitate wrong action confers final disvalue on an agent's FMP when she exercises it successfully? ${ }^{20}$

At a minimum, I think we should believe that the final value of FMP is not wholly grounded in what its successful exercise achieves. In all likelihood, it is not largely thus grounded either, given standard liberal thoughts about the value of agency. Indeed, when our axiological picture is sufficiently nuanced, reserving a place for the instrumental value of FMP, I do not feel any pull toward including the goodness of successful exercise in a general account of FMP's final value. (And only slightly more pull when thinking about particular agents' well-functioning FMPs.) Consequently, I am yet to see that the obligation to respect another agent's FMP generates DUTY, and therefore the wrongfulness of entrapment and similar phenomena.

If a regulative obligation to respect FMP would require support for even defective exercises, could that obligation exist? The question suggests a modus tollens. Nevertheless, I think we can affirm the basic duty as long as we endorse a fairly minimalist picture of what respect for FMP involves.

Here is a suggestion: it involves providing agents with the fundamental conditions for reasoning to, and acting from, moral conclusions. These include: ad-

19 See Korsgaard, Creating the Kingdom of Ends, ch. 9, especially 250.

20 In fact, whether a particular agent's FMP has even instrumental value depends on how effective it is. So, I do not see how to reach a general, impersonal claim about the instrumental value of FMP. Is not that sort of claim just an abstraction from lots of claims about particular agents' FMPs? 
equate nutrition and sleep; the absence of avoidable brain injury, indoctrination, and excessive pain; decent secondary-level education; and the political liberties. We already know these things are important and overdetermined by obligation.

Admittedly, another fundamental condition might be a certain sphere of personal choice protected by moral claims against interference with wrongdoing. Certain moral rights to do wrong might well be necessary for the autonomous self-constitution of an integral moral character or identity. ${ }^{21}$ If so, then on some occasions we should stand back when an agent employs her FMP unsuccessfully. Plus, for the protected sphere to be meaningfully wide, it will probably include some choices to wrong other agents: to betray a partner or break a promise, say, even if not to murder and rape. Thus, respect for moral agency might yet be a morally uncomfortable business on my proposal, beyond anodyne requirements like keeping people nourished and not torturing them. Indeed, even if interference with wrongdoing is always all-things-considered permissible, it might be a pro tanto wrong that warrants a measure of regret.

\section{V}

Suppose Howard remains committed to disconnecting respect for FMP from respect for defective exercises of FMP. While thereby avoiding the question of rights to do wrong, he must shift his grounds for opposing entrapment away from respecting agency. One line might be that acting wrongly is intrinsically bad for an agent, so that to increase the chance of her acting wrongly is to threaten her welfare. However, this claim would have to grapple with the grounds of FMP's final value, since the intrinsic effect of one's wrongdoing on one's welfare surely depends on the nature of agency. Indeed, the current proposal risks denying the content independence about the final value of agency that I have tried to motivate. Furthermore, we should guard against confusing the plausible idea that moral vices are bad for an agent with the idea that acting wrongly is bad for her even if it is at odds with her (excellent) character.

A more compelling shift of focus, in my view, would be toward something mentioned earlier: the telos of FMP. If we can say that FMP aims at right action, then perhaps we can build a case for the wrongness of interfering with its realization. It could be essential to this argument that right action has final value; after all, interfering with the telos of a screwdriver is not intrinsically wrong, since turning screws is only instrumentally valuable. But questions about the final value of FMP could be bypassed, and the standard liberal grounding accepted. On the other hand, given that the aim of FMP need not be any particular agent's aim,

21 See, in particular, Herstein, "Defending the Right to Do Wrong," especially 357-61. 
this strategy might struggle to justify a directed duty not to entrap, one whose violation would wrong the entrapped person. ${ }^{22}$

To retain the idea that FMP is a genuine power whose exercise demands respect, we would have to construe FMP's telos in terms of generating right action for the right reasons, or otherwise in a way bringing credit to the agent. If so, then some inducements to do right will be condemned, for instance, offers that generate a desire so overwhelming that the agent's judgment is suspended. ${ }^{23}$ One challenge would be to explain why interference with a telos is the real problem here, instead of suspension of agency. Another challenge, if one accepts the permissibility of pro-moral, subrational "nudges," would be to show how these can evade censure by the current proposal. ${ }^{24}$

That sketchy proposal aside, my own telos here has been to cast doubt on the attempt to derive DUTY from an obligation to respect FMP, and thereby-more importantly—to undermine a recent argument for the intrinsic (and directed) wrongness of ordinary as well as structural entrapment.

If I am right, systematic social injustice is somewhat less wrongful than Howard believes. However, the practical implications of my paper are far greater for the conduct of law enforcement than for general matters of social and economic policy. Whether or not Howard's argument is correct, we have overriding reason to change government policies that encourage or allow deprivation. The systematic thwarting of people's life chances already has little if anything to be said for it, and much to be said against it. In law enforcement cases, though, Howard's argument seems more likely to make an all-things-considered deontic difference. And this is for two reasons.

First, there is sometimes a prima facie case for testing an individual's proclivity toward serious wrongdoing, and seeking to contain it by establishing grounds for conviction. Not least, it can (significantly) reduce the probability of serious harm to (large numbers of) innocent people. Second, the most obvious typical features of entrapment-including manipulation, deception, and the state aiming to restrict substantially the liberty of a citizen —are difficult to view as

22 A point somewhat obscured by Howard's talk of our "quests to be just persons." See Howard, "Moral Subversion and Structural Entrapment," 25.

23 See Frankfurt, "Coercion and Moral Responsibility," 41-42. In the same boat are "Pavlovian" inducements to do right, which risk making an agent dependent on certain cues or rewards in order to act rightly.

24 See Thaler and Sunstein, Nudge. 
absolutely impermissible. So, in positing a regulative, constraint-imposing duty not to entrap, Howard promised to do much more than throw a defeasible anti-entrapment consideration into the mix. The failure of his argument is an especial loss to opponents of ordinary entrapment-a practice that I am inclined to believe is sometimes permissible and even obligatory in our nasty, dangerous world.

\author{
University of Oxford \\ jonathan.stanhope@mansfield.ox.ac.uk
}

\title{
REFERENCES
}

Dworkin, Gerald. "Paternalism." In Mill's On Liberty: Critical Essays, 61-82. Oxford: Rowman and Littlefield, 1997.

Enoch, David. "Agency, Shmagency: Why Normativity Won't Come from What Is Constitutive of Action." Philosophical Review 115, no. 2 (April 2006): 16998.

Frankfurt, Harry. "Coercion and Moral Responsibility." The Importance of What We Care About. New York: Cambridge University Press, 1988.

Freeman, Samuel, ed. The Cambridge Companion to Rawls. Cambridge: Cambridge University Press, 2003.

Herstein, Ori J. "Defending the Right to Do Wrong." Law and Philosophy 31, no. 3 (May 2012): 343-65.

Howard, Jeffrey W. "Moral Subversion and Structural Entrapment." Journal of Political Philosophy 24, no. 1 (March 2016): 24-46.

Korsgaard, Christine M. Creating the Kingdom of Ends. Cambridge: Cambridge University Press, 1996.

Mandle, Jon, and David A. Ready, eds. A Companion to Rawls. Chichester: Wiley-Blackwell, 2014.

Rawls, John. Political Liberalism. New York: Columbia University Press, 2005. Thaler, Richard H., and Cass R. Sunstein. Nudge: Improving Decisions about Health, Wealth and Happiness. New Haven: Yale University Press, 2008. 